\title{
Effect of inseminating cows in estrus following a presynchronization protocol on reproductive and lactation performances
}

\author{
R. C. Chebel ${ }^{* 1}$ and J. E. P. Santos $†$ \\ *Department of Veterinary Population Medicine, University of Minnesota, Saint Paul 55108 \\ †Department of Animal Sciences, University of Florida, Gainesville 32611
}

\begin{abstract}
Objectives were to evaluate the effects of inseminating cows observed in estrus following a $\mathrm{PGF}_{2 \alpha}$-based presynchronization protocol on reproductive and lactation performance. Weekly, Holstein cows (260 primiparous and 379 multiparous) were balanced by parity, body condition score at $3 \mathrm{~d}$ in milk (DIM), and previous lactation milk yield (multiparous cows) and assigned randomly to either of 2 reproductive programs. All cows received 2 injections of $\mathrm{PGF}_{2 \alpha}$ at 35 and $49 \mathrm{DIM}$ and a controlled internal drug release insert containing progesterone from 42 to 49 DIM. Cows assigned to the short voluntary waiting period (SVWP) treatment were inseminated if observed in estrus after the second injection of $\mathrm{PGF}_{2 \alpha}$ of the presynchronization protocol, and those not inseminated were submitted to a timed artificial insemination (TAI) protocol (GnRH 62 DIM, $\mathrm{PGF}_{2 \alpha} 69$ DIM, GnRH 71 DIM, and TAI 72 DIM), whereas cows assigned to the long voluntary waiting period (LVWP) were all submitted to the TAI protocol and were TAI at 72 DIM. Plasma progesterone was determined at 35, 49, and 62 DIM for evaluation of interval from parturition to resumption of cyclicity. Pregnancy was diagnosed weekly at 32 and $60 \mathrm{~d}$ after first $\mathrm{AI}$ and at $42 \mathrm{~d}$ after subsequent inseminations. Percentage of SVWP cows inseminated in estrus was $58.9 \%$ and the interval from parturition to first AI was shorter for SVWP cows $(64.7 \pm 0.4$ vs. $74.2 \pm 0.5$ DIM). Cows cyclic by 49 and 62 DIM were more likely to be inseminated in estrus than those anovular by 62 DIM $(67.9,61.0$, and $32.8 \%$, respectively) and cyclic cows by 49 and 62 DIM had shorter interval from parturition to first AI than anovular cows $(62.6 \pm 0.7,63.1 \pm 1.2$, and $70.1 \pm 1.1$ DIM). Treatment did not affect pregnancy per AI after first postpartum AI or the rate at which cows became pregnant. Cows that resumed cyclicity by 49 DIM had greater pregnancy per AI than cows still anovular by 62 DIM and became pregnant at a faster
\end{abstract}

Received February 17, 2010.

Accepted June 12, 2010.

${ }^{1}$ Corresponding author: chebe002@umn.edu rate than cows that resumed cyclicity by 62 DIM and those still anovular by 62 DIM. Inseminating cows that displayed estrus after the presynchronization protocol did not affect reproductive performance compared with submission of $100 \%$ of cows to a TAI protocol.

Key words: dairy cow, voluntary waiting period, reproductive performance

\section{INTRODUCTION}

Reproductive management strategies adopted by many dairy producers are necessary because of poorer reproductive performance of lactating dairy cows observed in the past decades, which is in part a consequence of increased incidence of anovular condition and reduced rate of submission to AI. A critical part of such reproductive management strategies for herds that face the problems described above is the submission of cows to ovulation synchronization protocols that allow for timed AI (TAI). In one comprehensive survey conducted in 103 dairy herds from at least 12 states, an estrus/ ovulation synchronization program for first postpartum AI was implemented in $74.8 \%$ of the herds (Caraviello et al., 2006). When data from 33 million inseminations of Holstein and Jersey cows from DHIA herds were analyzed, however, it was estimated that the percentage of herds that did not use synchronization protocols was $94.8 \%$ in 1996 and $72.5 \%$ in 2005 (Miller et al., 2007). The implementation of such synchronization protocols resulted in reduced intervals from parturition to first postpartum AI and reduced variability in interval to first postpartum AI, and could arguably have reduced the interval from parturition to establishment of a new pregnancy (Miller et al., 2007).

Questions remain, however, regarding the ideal voluntary waiting period (VWP; period after parturition during which cows are intentionally not inseminated). According to 2 different surveys, the duration of the VWP in approximately 800 dairy herds across the United States was between 53 and 56 d (DeJarnette et al., 2007; Caraviello et al., 2006), and, according to Miller et al. (2007), nearly $70 \%$ of herds have at least $10 \%$ of cows inseminated before 60 DIM. Several factors must 
be considered when making a decision regarding the VWP: incidence of postparturient disorders, incidence of anovular condition and length of anovular period, potential gains and losses in pregnancy per AI (P/AI), milk yield and persistency of the lactation curve, parity, and so on.

Most studies evaluating fixed-time AI protocols for first postpartum AI were designed so that $100 \%$ of cows submitted to such protocols were inseminated at a fixed time. When $\mathrm{PGF}_{2 \alpha}$-based presynchronization protocols are implemented before TAI systems, however, it is expected that a large percentage of cyclic cows display estrus. Recent studies have demonstrated that approximately $55 \%$ of cows presynchronized with 2 injections of $\mathrm{PGF}_{2 \alpha}$ were inseminated based on signs of estrus before the completion of the timed AI protocol (Stevenson and Phatak, 2005; Lima et al., 2009; Chebel et al., 2010). Further, there were no differences in P/ AI between cows inseminated at estrus and those completing the TAI protocol (Stevenson and Phatak, 2005; Lima et al., 2009; Chebel et al., 2010).

The hypothesis of the present study was that inseminating cows observed in estrus after the presynchronization protocol would not affect first postpartum AI $\mathrm{P} / \mathrm{AI}$ and reproductive performance after 305 DIM compared with submission of all cows to a TAI protocol. Therefore, the objectives of the current study were to evaluate the effect of inseminating cows observed in estrus after a presynchronization protocol on lactation performance and economic outcome after 305 DIM.

\section{MATERIALS AND METHODS}

\section{Animals, Housing, Diets, and Postparturient Diseases}

Lactating Holstein cows $(\mathrm{n}=639)$ from a commercial dairy farm with a rolling herd average of $12,035 \mathrm{~kg}$ of $3.5 \%$ FCM were used in this study. Cows were housed in freestall barns with adjacent exercise open lots. Cows were fed twice daily and diets were based on corn silage, alfalfa hay, soybean meal, steam-rolled corn, whole cottonseed, calcium salts of palm oil, and a mineral and vitamin supplement. Diets were formulated to meet or exceed the requirements set forth by the NRC (2001) for lactating Holstein cows weighing $650 \mathrm{~kg}$ and producing $45 \mathrm{~kg}$ of $\mathrm{FCM} / \mathrm{d}$.

Postparturient diseases such as retained fetal membranes (fetal membranes retained for at least $12 \mathrm{~h}$ after parturition), displacement of the abomasum (metallic sound in the ventro-cranial left abdomen), clinical mastitis (alteration in milk appearance or inflamed mammary gland), and lameness (cow unable to partially sustain weight in one or multiple limbs) were diagnosed by farm personnel and recorded in an on-farm computer software. These data were extracted from the on-farm computer software and cows were classified as having or not having any of the diseases described above.

\section{Synchronization of the Estrous Cycle for First Postpartum Al}

Weekly, cows between 25 and 31 DIM were balanced by parity, BCS at 3 DIM, and previous lactation milk yield (multiparous), and were randomly assigned to 1 of 2 treatments: short voluntary waiting period (SVWP) or long voluntary waiting period (LVWP). All cows were presynchronized with 2 injections of $\mathrm{PGF}_{2 \alpha}(25$ $\mathrm{mg}$ of dinoprost tromethamine; Lutalyse, Pfizer Animal Health, New York, NY) given at 35 and 49 DIM and a controlled internal drug release (CIDR) insert containing $1.38 \mathrm{~g}$ of progesterone (Eazi-Breed CIDR insert, Pfizer Animal Health) from 42 to 49 DIM. Cows in the SVWP treatment were inseminated if observed in estrus after the second injection of $\mathrm{PGF}_{2 \alpha}$, given at 49 DIM. All LVWP cows and SVWP cows not inseminated by 62 DIM were submitted to the Ovsynch protocol [GnRH $(100 \mu \mathrm{g}$ of gonadorelin diacetate tetrahydrate, Cystorelin, Merial Ltd., Iselin, NJ) at 62 DIM, PGF $2 \alpha$ at 69 DIM, and GnRH at 71 DIM] and were inseminated at fixed time at 72 DIM. Therefore, the VWP of SVWP cows was $49 \pm 3$ DIM and that of LVWP cows was $72 \pm 3$ DIM.

\section{Estrous Detection and AI}

Cows were observed daily in the morning for signs of behavioral estrus and signs of estrus based on removal of tail paint (All-weather Paintstick, LA-CO Industries, Chicago, IL). Only SVWP cows were inseminated on detected estrus between 49 and 71 DIM. After the first postpartum AI, all cows observed in estrus were reinseminated on detected estrus.

One technician inseminated cows on $6 \mathrm{~d}$ of the week and a relief technician inseminated cows once a week. On the day of fixed-time AI, all cows were inseminated by one technician. Therefore, $94.4 \%$ of cows were inseminated by one technician.

\section{Blood Samples, Progesterone Assay, and Characterization of Anovular Condition}

Blood $(7 \mathrm{~mL})$ was sampled at 35,49 , and 62 DIM from the median coccygeal vein or artery using evacuated tubes (Becton Dickinson, Franklin Lakes, NJ) containing Na EDTA. Samples were immediately placed in ice and transported to the laboratory within $5 \mathrm{~h}$ of collection. Blood tubes were centrifuged at 2,000 $\times g$ 
for 15 min to separate plasma. Plasma samples were frozen at $-25^{\circ} \mathrm{C}$ and later analyzed for progesterone by an ELISA validated for bovine plasma (Cerri et al., 2004). At 49 DIM, blood samples were collected $30 \mathrm{~min}$ after the removal of the CIDR insert to avoid the confounding effect of exogenous progesterone on plasma progesterone concentrations of anovular cows (Cerri et al., 2009).

Cows with plasma progesterone concentration $<1$ $\mathrm{ng} / \mathrm{mL}$ in all samples were considered to be anovular by 62 DIM (ANOV62), cows with plasma progesterone concentration $<1 \mathrm{ng} / \mathrm{mL}$ at 35 and 49 DIM and progesterone concentration $\geq 1 \mathrm{ng} / \mathrm{mL}$ at 62 DIM were considered to have resumed cyclicity by 62 DIM (CYC62), and those with plasma progesterone concentration $\geq 1 \mathrm{ng} / \mathrm{mL}$ at 35 or 49 DIM were considered to have resumed cyclicity by 49 DIM (CYC49).

\section{BCS}

Cows were evaluated for BCS $(1=$ emaciated, $5=$ obese) at 3, 35, and 62 DIM as described previously (Ferguson et al., 1994). For the purpose of statistical analyses, cows were classified according to BCS at 62 DIM as BCS $\leq 2.75$ and BCS $>2.75$. Cows were also classified according to BCS change (BCSC) from 3 to $62 \mathrm{DIM}$ as $\mathrm{BCSC} \leq-1$ unit, $\mathrm{BCSC}=-0.25$ to -0.75 unit, and $\mathrm{BCSC} \geq 0$ unit.

\section{Pregnancy Diagnosis}

After the first postpartum AI, cows were examined by ultrasound at $32 \mathrm{~d}$ after AI and pregnancy was characterized by visualization of an embryo. Pregnant cows were reexamined by palpation per rectum of the uterine contents at $60 \mathrm{~d}$ after AI. Cows inseminated 2 or more times after the first postpartum AI were examined for pregnancy diagnosis by palpation per rectum of the uterine contents at $42 \mathrm{~d}$ after AI. On the day of non-pregnancy diagnosis, cows that had not been reinseminated were enrolled in the Ovsynch protocol for resynchronization and reinsemination. Cows reinseminated before being examined for pregnancy diagnosis were considered not pregnant to the previous AI.

\section{Reproductive Outcomes}

Interval from parturition to first postpartum AI was calculated for each cow. Percentages of SVWP cows inseminated before the start of the Ovsynch protocol (62 DIM) and before the $\mathrm{PGF}_{2 \alpha}$ injection of the Ovsynch protocol (at 69 DIM) were calculated. Pregnancy per AI was calculated by dividing the number of cows pregnant at different intervals after AI by the number of cows inseminated. Pregnancy loss was calculated by dividing the number of cows not pregnant at $60 \mathrm{~d}$ after first postpartum AI by the number of cows pregnant at $32 \mathrm{~d}$ after first postpartum AI. The interval between parturition and pregnancy was calculated for each individual cow, and cows that left the herd before diagnosis of pregnancy and cows that were not pregnant after 305 DIM were right censored for the interval between parturition and establishment of a new pregnancy. To evaluate the association between DIM at establishment of a new pregnancy on milk yield, DIM at establishment of a new pregnancy was divided into quartiles. Number of inseminations per cow during the first 305 DIM was recorded until pregnancy was diagnosed or until the cow left the herd. Percentage of cows pregnant at the end of 305 DIM was calculated by dividing the number of cows pregnant at 305 DIM by the number of cows initially enrolled in the study.

\section{Milk Yield}

Cows were milked 3 times daily and milk yields were recorded for individual cows once a month during the official California DHIA test. Monthly milk samples were analyzed for fat and true protein concentrations at the DHIA laboratory in Tulare, California. All cows received $500 \mathrm{mg}$ of recombinant bST (Posilac, Monsanto Co., St. Louis, MO) every $14 \mathrm{~d}$, starting at 100 \pm 3 DIM. Monthly FCM was recorded from parturition until cows were dried-off, or until 305 DIM, or until cows left the herd.

\section{Economic Analysis}

For purposes of economic analysis of the different reproductive managements, the following values were used: labor $=\$ 10 / \mathrm{h}, \mathrm{GnRH}=\$ 2 /$ injection, $\mathrm{PGF}_{2 \alpha}=$ $\$ 2 /$ injection, CIDR insert $=\$ 10 /$ insert, labor/injection $=1 \mathrm{~min}$, labor $/$ CIDR insertion and removal $=3 \mathrm{~min}$, and labor for daily estrus detection $=15 \mathrm{~s} / \mathrm{cow}$ per day.

Although in the current study LVWP and SVWP cows were housed together in multiple pens and the AI technician examined all cows for signs of estrus daily, theoretically cows in the LVWP would not need to be observed daily for estrus until the first postpartum AI. Therefore, no cost of estrus detection was assessed to LVWP cows. On the other hand, because SVWP cows would have to be observed for estrus daily, regardless if they had been inseminated, all SVWP cows were assessed the cost of estrus detection for $23 \mathrm{~d}$ (interval from the end of the VWP to the day of TAI). Because 
reproductive management of SVWP and LVWP cows was the same after first postpartum AI, no calculations of reproductive program cost were made after 72 DIM.

Income over feed cost (IOFC) was calculated to be $\$ 0.06 / \mathrm{kg}$ of FCM, and total IOFC was calculated by multiplying total milk yield by IOFC. Cows that were not pregnant by 305 DIM and cows that were removed from the herd before completing 305 DIM were defined to be cull cows and as such were given a salvage value $(\$ 400 /$ cow $)$ and a replacement cost value $(\$ 1,400 /$ cow).

Economic balance was calculated for individual cows as follows: Economic balance $=($ total $\mathrm{IOFC}+$ salvage value) - (reproductive management cost for first $\mathrm{AI}+$ replacement value).

\section{Study Design and Statistical Analysis}

The study was a completely randomized design. Cows were balanced for parity, BCS at 3 DIM, and milk yield in the previous lactation (multiparous) and assigned randomly to either the SVWP or LVWP treatments. The number of experimental units (cow) initially planned per treatment (300 cows) was expected to provide sufficient power to determine statistical significance when $\mathrm{P} / \mathrm{AI}$ after first postpartum AI between treatments differed by 8 percentage units and $\mathrm{P} / \mathrm{AI}$ after first postpartum AI ranges from 30 to $40 \%$ $(\alpha=0.05 ; \beta=0.80)$. Furthermore, the number of experimental units was expected to provide enough power to determine statistical significance when percentage of cows pregnant at 305 DIM between treatments differed by 6.8 percentage units when percentage of pregnant cows at 305 DIM varied between 75 and $85 \%(\alpha=0.05$; $\beta=0.80)$.

The statistical software used for all analyses was SAS (SAS Institute Inc., Cary, NC). Percentages of SVWP and LVWP cows that were CYC49, CYC62, or ANOV62 were compared by chi-squared test using the FREQ procedure. Other dichotomous outcomes were analyzed by logistic regression using the LOGISTIC procedure. The logistic regression models removed variables by a backward elimination based on the Wald's statistic criterion when $P>0.1$. For analysis of factors that affected resumption of cyclicity, the model included parity (primiparous vs. multiparous), BCS at 62 DIM (BCS $\leq 2.75$ vs. BCS $>2.75$ ), and change in BCS from 3 to 62 DIM (no change or gain in BCS, BCS loss between 0.25 and 0.75 unit, and BCS loss $\geq 1$ unit). For analysis of factors that affected the percentage of SVWP cows inseminated in estrus before 62 and 69 DIM, the model included parity and interval to resumption of cyclicity (CYC49, CYC62, and ANOV62). Models for analyses of $\mathrm{P} / \mathrm{AI}$ and percentage of cows pregnant by $305 \mathrm{DIM}$ included treatment, parity, interval to resumption of cyclicity, and relevant interactions.

Continuous data were analyzed by ANOVA using the GLM procedure, and all models initially included treatment, parity, and interval to resumption of cyclicity, but if variables had $P>0.1$ they were removed from the model. The final model used to analyze the interval from parturition to first postpartum AI included treatment, interval to resumption of cyclicity, and their interaction. Number of inseminations until pregnancy was diagnosed, or 305 DIM, or until cows left the herd was analyzed with a final model that included treatment, parity, interval to resumption of cyclicity, and relevant interactions.

Reproductive management cost for first AI had a nonnormal distribution and was analyzed by KruskalWallis with a Poisson distribution using the GENMOD procedure. For analysis of reproductive management cost for first AI, the initial model included treatment, parity, interval to resumption of cyclicity, and interactions, but the final model included treatment, interval to resumption of cyclicity, and their interaction. Replacement cost and salvage value had a binomial distribution and as such were analyzed by Kruskal-Wallis with a binomial distribution using the GENMOD procedure. The models initially included treatment, parity, interval to resumption of cyclicity, and their interactions. The final models did not include any interactions because they were not significant.

The rate at which cows became pregnant was analyzed by the Cox proportional hazards regression using the PHREG procedure, and adjusted hazard ratio (AHR) and 95\% confidence intervals were calculated. The model included treatment, interval to resumption of cyclicity, and relevant interactions. To determine the effect of inseminating SVWP CYC49 cows in estrus between 49 and 72 DIM on reproductive performance, the rate at which $\mathrm{CYC} 49$ cows became pregnant was analyzed using a model that included treatment, type of insemination (SVWP cows inseminated in estrus and SVWP and LVWP cows inseminated at fixed time), parity, BCS at 62 DIM, yield FCM during the first 3 mo of lactation, and interactions.

The effects of selected variables on the interval between parturition and pregnancy were analyzed by survival analysis using the product limit method of the Kaplan-Meier model using the LIFETEST procedure.

Yield of FCM was analyzed by ANOVA for repeated measures using the MIXED procedure with a model that initially included treatment, parity, interval to resumption of cyclicity, BCS at 62 DIM, DIM at pregnancy classified into quartiles, test number, and the interactions between treatment and test number and between DIM at pregnancy classified into quartiles and 
Table 1. Effect of inseminating cows in estrus following a presynchronization protocol on reproductive performance of lactating Holstein cows

\begin{tabular}{|c|c|c|c|}
\hline \multirow[b]{2}{*}{ Item } & \multicolumn{2}{|c|}{ Treatment $^{1}$} & \multirow[b]{2}{*}{$P$-value } \\
\hline & SVWP & LVWP & \\
\hline Cows, $\mathrm{n}$ & 321 & 318 & \\
\hline Resumption of cyclicity $^{2}$ & & & 0.70 \\
\hline Cyclic cows at 49 DIM, $\%$ & 59.7 & 62.8 & \\
\hline Cyclic cows at 62 DIM, $\%$ & 18.9 & 18.3 & \\
\hline Anovular at 62 DIM, \% & 21.4 & 19.0 & \\
\hline Percentage inseminated at estrus at first AI, \% & 58.9 & 0.0 & $<0.01$ \\
\hline DIM at first $\mathrm{AI}( \pm$ SEM $)$ & $64.7 \pm 0.4$ & $74.2 \pm 0.5$ & $<0.01$ \\
\hline $\mathrm{P} / \mathrm{AI}^{3}$ at $32 \mathrm{~d}$ after first $\mathrm{AI}, \%$ & 33.0 & 39.6 & 0.14 \\
\hline $\mathrm{P} / \mathrm{AI}$ at $60 \mathrm{~d}$ after first $\mathrm{AI}, \%$ & 25.3 & 31.1 & 0.20 \\
\hline Pregnancy loss from 32 to $60 \mathrm{~d}$ after first AI, $\%$ & 22.9 & 21.4 & 0.97 \\
\hline $\mathrm{P} / \mathrm{AI}$ at $42 \mathrm{~d}$ after second $\mathrm{AI}, \%$ & 33.5 & 26.0 & 0.04 \\
\hline Percentage pregnant at 305 DIM, $\%$ & 76.3 & 73.9 & 0.10 \\
\hline Hazard ratio for pregnancy $(95 \%$ CI) & $\begin{array}{l}1.12 \\
(0.94,1.35)\end{array}$ & Referent & 0.22 \\
\hline Inseminations, $\mathrm{n}( \pm \mathrm{SEM})$ & $3.58 \pm 0.17$ & $3.79 \pm 0.17$ & 0.31 \\
\hline
\end{tabular}

${ }^{1}$ All cows were presynchronized with 2 injections of $\mathrm{PGF}_{2 \alpha}$ given at 35 and 49 DIM and a controlled internal drug release insert containing $1.38 \mathrm{~g}$ of progesterone from 42 to 49 DIM. The SVWP (short voluntary waiting period) cows were inseminated if observed in estrus after the second injection of $\mathrm{PGF}_{2 \alpha}$. All LVWP (long voluntary waiting period) cows and SVWP cows not inseminated by 62 DIM were submitted to the Ovsynch protocol (GnRH at 62 DIM, $\mathrm{PGF}_{2 \alpha}$ at $69 \mathrm{DIM}$, and $\mathrm{GnRH}$ at $71 \mathrm{DIM}$ ) and were inseminated at fixed time at 72 DIM.

${ }^{2}$ Cows with plasma progesterone concentration $<1 \mathrm{ng} / \mathrm{mL}$ in all samples were considered to be anovular by 62 DIM; cows with plasma progesterone concentration $<1 \mathrm{ng} / \mathrm{mL}$ at 35 and 49 DIM and progesterone concentration $\geq 1 \mathrm{ng} / \mathrm{mL}$ at 62 DIM were considered to have resumed cyclicity by 62 DIM; and those with plasma progesterone concentration $\geq 1 \mathrm{ng} / \mathrm{mL}$ at 35 or 49 DIM were considered to have resumed cyclicity by 49 DIM.

${ }^{3}$ Pregnancy per AI.

test number. The final model included treatment, parity, BCS at 62 DIM, DIM at pregnancy classified into quartiles, test number, and the interaction between DIM at pregnancy classified into quartiles and test number. According to Schwarz's Bayesian information criterion, the best covariance structure was unstructured.

\section{RESULTS}

Percentage of CYC49, CYC62, and ANOV62 cows was not $(P=0.70)$ different between treatments (Table 1). Primiparous cows were less $(P=0.01)$ likely to be cyclic by 49 DIM than were multiparous cows (50.6 vs. $68.4 \%$ ), and cows with BCS $\leq 2.75$ at 62 DIM were less likely $(P=0.01)$ to be cyclic by 49 DIM than cows with BCS $>2.75$ at 62 DIM (55.7 vs. $69.6 \%$; Table 1). Percentages of SVWP and LVWP cows that were diagnosed with periparturient diseases were not $(P=$ 0.17 ) different (average of SVWP and LVWP cows = $20.6 \%$ ).

\section{Reproductive Performance}

Among SVWP cows, $58.9 \%$ were inseminated at estrus (Table 1), with $48.9 \%$ of cows inseminated between 49 and 62 DIM, 3.7\% of cows inseminated between 63 and 69 DIM, and $6.2 \%$ of cows inseminated between 70 and 72 DIM. Consequently, interval from parturition to first postpartum AI was shorter $(P<0.01)$ for SVWP cows compared with LVWP cows. Among SVWP cows, CYC49 and CYC62 were more $(P<0.01)$ likely to be inseminated in estrus and had shorter $(P<0.01)$ interval from parturition to first postpartum AI than ANOV62 cows (Table 2).

Pregnancies per AI at $32 \mathrm{~d}(P=0.14)$ and $60 \mathrm{~d}(P$ $=0.20$ ) resulting from first postpartum AI did not differ between treatments (Table 1). Among SWVP cows, there were no differences in $\mathrm{P} / \mathrm{AI}$ at $32(P=0.31)$ and $60(P=0.20) \mathrm{d}$ after first postpartum AI between cows inseminated at estrus (32.3 and $23.9 \%$, respectively) or at fixed time (34.1 and $27.3 \%$, respectively). At $32 \mathrm{~d}$ after first postpartum AI, CYC49 and CYC62 were more $(P<0.01)$ likely to be pregnant than ANOV62 cows (Table 2). At $60 \mathrm{~d}$ after first postpartum AI, CYC49 cows had greater $(P<0.01) \mathrm{P} / \mathrm{AI}$ than ANOV62 cows, and CYC62 cows tended $(P=0.07)$ to have greater $\mathrm{P} /$ AI than ANOV62 (Table 2). Parity did not affect $\mathrm{P} / \mathrm{AI}$ at $32(P=0.81)$ or $60(P=0.28)$ after first postpartum AI. Average yield of FCM during the first 3 mo of lactation had no effect on $\mathrm{P} / \mathrm{AI}$ at $32(P=0.71)$ or $60(P=0.39)$ after first postpartum AI. Percentage of cows that had pregnancy loss from 32 to $60 \mathrm{~d}$ after 
Table 2. Reproductive performance of lactating Holstein cows according to the interval from parturition to resumption of cyclicity

\begin{tabular}{|c|c|c|c|c|}
\hline Item & \multicolumn{3}{|c|}{ Interval to resumption of cyclicity ${ }^{1}$} & $P$-value \\
\hline Percentage inseminated at estrus at first $\mathrm{AI},{ }^{3} \%$ & $67.9^{\mathrm{a}}$ & $61.0^{\mathrm{a}}$ & $32.8^{\mathrm{b}}$ & $<0.01$ \\
\hline DIM at first $\mathrm{AI}^{3}( \pm$ SEM $)$ & $62.6 \pm 0.7^{\mathrm{a}}$ & $63.1 \pm 1.2^{\mathrm{a}}$ & $70.1 \pm 1.1^{\mathrm{b}}$ & $<0.01$ \\
\hline $\mathrm{P} / \mathrm{AI}^{4}$ at $32 \mathrm{~d}$ after first $\mathrm{AI}, \%$ & $41.7^{\mathrm{a}}$ & $34.8^{\mathrm{a}}$ & $23.2^{\mathrm{b}}$ & $<0.01$ \\
\hline $\mathrm{P} / \mathrm{AI}$ at $42 \mathrm{~d}$ after second $\mathrm{AI}, \%$ & 30.4 & 29.8 & 27.2 & 0.61 \\
\hline Pregnant at 305 DIM, \% & $79.7^{\mathrm{a}}$ & $69.6^{\mathrm{b}}$ & $64.8^{\mathrm{b}}$ & $<0.01$ \\
\hline Hazard ratio for pregnancy (95\% CI) & Referent $^{\mathrm{a}}$ & $0.75(0.58,0.96)^{\mathrm{b}, \mathrm{A}}$ & $0.56(0.43,0.72)^{\mathrm{b}, \mathrm{B}}$ & $<0.01$ \\
\hline Inseminations, $\mathrm{n}( \pm \mathrm{SEM})$ & $3.33 \pm 0.16^{\mathrm{a}}$ & $3.59 \pm 0.25^{\mathrm{A}}$ & $4.13 \pm 0.23^{\mathrm{b}, \mathrm{B}}$ & $<0.01$ \\
\hline
\end{tabular}

${ }^{\mathrm{a}, \mathrm{b}}$ Within rows, values with different superscripts differ $(P<0.05)$.

${ }^{\mathrm{A}, \mathrm{B}}$ Within rows, values with different superscripts tended to differ $(P<0.10)$.

${ }^{1}$ Cows with plasma progesterone concentration $<1 \mathrm{ng} / \mathrm{mL}$ in all samples were considered to be anovular by 62 DIM, cows with plasma progesterone concentration $<1 \mathrm{ng} / \mathrm{mL}$ at 35 and $49 \mathrm{DIM}$ and progesterone concentration $\geq 1 \mathrm{ng} / \mathrm{mL}$ at 62 DIM were considered to have resumed cyclicity by $62 \mathrm{DIM}$, and those with plasma progesterone concentration $\geq 1 \mathrm{ng} / \mathrm{mL}$ at 35 or 49 DIM were considered to have resumed cyclicity by 49 DIM.

${ }^{2}$ The first or second blood samples were not collected from 20 cows; therefore, determination of cyclic status was not possible.

${ }^{3}$ Analysis included only SVWP (short voluntary waiting period) cows.

${ }^{4}$ Pregnancy per AI.

first postpartum AI was not affected by treatment $(P=$ 0.97 ; Table 1$)$, by the interval to resumption of cyclicity $(P=0.70 ;$ Table 2$)$, or by parity $(P=0.18)$.

Interestingly, $\mathrm{P} / \mathrm{AI}$ after second postpartum $\mathrm{AI}$ was greater $(P=0.04)$ for SVWP than for LVWP cows (Table 1), but the interval to resumption of cyclicity did not $(P=0.61)$ affect $\mathrm{P} / \mathrm{AI}$ after second postpartum AI (Table 2). Although parity had no $(P=0.54)$ effect on $\mathrm{P} / \mathrm{AI}$ after second postpartum $\mathrm{AI}$, the interaction between treatment and parity affected $(P=0.01) \mathrm{P} /$ AI after the second postpartum AI, because among multiparous cows treatment had no effect on P/AI (28.4\%), but among primiparous cows those in the SVWP treatment had greater P/AI than those in the LVWP treatment (41.8 vs. $21.5 \%$ ).

Percentage of cows pregnant by 305 DIM tended $(P$ $=0.10)$ to be greater for SVWP than for LVWP cows (Table 1$)$. Cows cyclic by 49 DIM were more $(P<$ 0.01) likely to be pregnant by 305 DIM than CYC62 and ANOV62 cows, but there was no $(P=0.35)$ difference between CYC62 and ANOV62 cows (Table 2). Primiparous cows were more $(P=0.02)$ likely to be pregnant by 305 DIM than multiparous cows (78.1 vs. $73.1 \%$ ). Interestingly, the interaction between treatment and parity tended $(P=0.09)$ to affect the percentage of cows pregnant by 305 DIM, because although percentage of multiparous SVWP and LVWP cows pregnant at 305 DIM did not differ $(73.1 \%)$, a greater percentage of SVWP primiparous cows were pregnant at 305 DIM compared with LVWP primiparous cows (82.3 vs. $73.9 \%)$.
Treatment had no effect on the rate at which cows became pregnant $(P=0.22)$ or on the number of inseminations by 305 DIM $(P=0.31$; Table 1$)$. The mean $( \pm$ SEM) intervals from parturition to pregnancy were $154.0 \pm 4.7 \mathrm{~d}$ and $153.4 \pm 4.2 \mathrm{~d}$ for SVWP and LVWP cows, respectively (Figure 1). Interval to resumption of cyclicity affected $(P<0.01)$ the rate at which cows became pregnant because CYC49 cows became pregnant at a faster rate than $\mathrm{CYC} 62(P=0.02)$ and ANOV62 $(P<0.01)$ cows, whereas CYC62 cows tended $(P=$ $0.06)$ to become pregnant at a faster rate than ANOV62 cows (Table 2). Intervals from parturition to pregnancy were $143.5 \pm 4.0,158.3 \pm 7.5$, and $185.6 \pm 7.3 \mathrm{~d}$ for CYC49, CYC62, and ANOV62 cows, respectively ( $P$ $<0.01$; Figure 2). Although multiparous cows tended $(P=0.07)$ to become pregnant at a slower rate than primiparous cows (AHR $=0.84,95 \% \mathrm{CI}=0.70-1.01$ ), intervals from parturition to pregnancy were not different (primiparous $=152.8 \pm 5.0$, multiparous $=157.5 \pm$ $4.2 \mathrm{~d} ; P=0.60)$.

Among CYC49 cows, SVWP cows inseminated in estrus $(57.3 \pm 0.5 \mathrm{DIM})$ had shorter $(P<0.01)$ interval from parturition to first AI than SVWP cows inseminated at fixed time $(73.4 \pm 0.7 \mathrm{DIM})$ and LVWP cows $(74.1 \pm 0.4 \mathrm{DIM})$ but the latter 2 groups did not $(P=$ $0.35)$ differ. Treatment did not $(P=0.14)$ affect the hazard ratio for pregnancy (SVWP cows inseminated in estrus: $\mathrm{AHR}=1.25,95 \% \mathrm{CI}=0.97-1.62$; SVWP cows inseminated at fixed time: $\mathrm{AHR}=0.93,95 \% \mathrm{CI}=$ 0.66-1.30; LVWP = referent). According to the survival analysis, the interval between parturition and establish- 


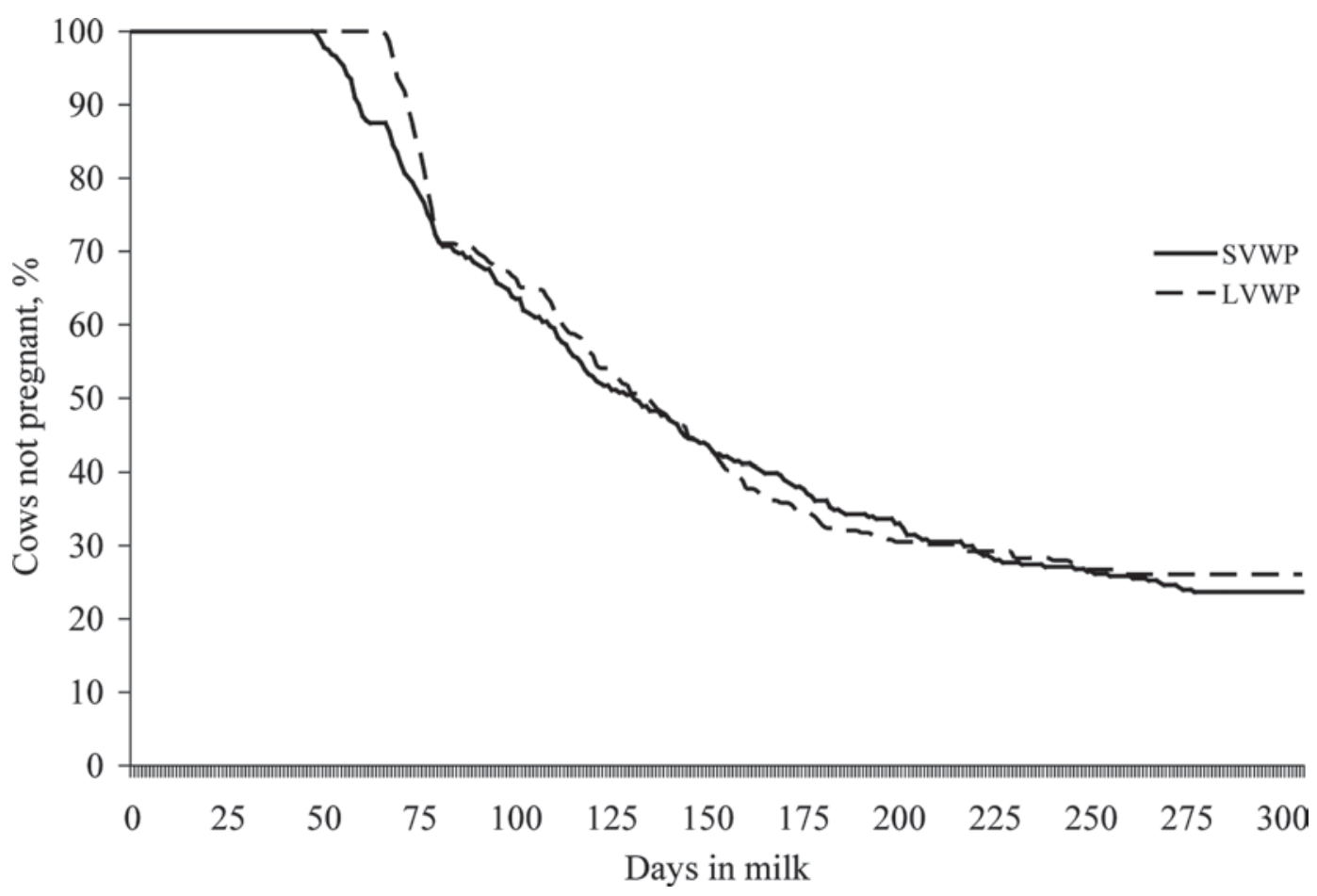

Figure 1. Survival analysis of interval from parturition to pregnancy according to length of the voluntary waiting period [VWP, short (S) and long $(\mathrm{L})]$. Effect of treatment on hazard ratio of pregnancy according to the Cox proportional analysis, $P=0.22$. Effect of treatment on interval from parturition to pregnancy according to the test of equality Wilcoxon based on the Kaplan-Meier model, $P=0.22$. Mean $( \pm$ SEM) and median interval from parturition to establishment of a new pregnancy: SVWP $=154.0 \pm 4.7$ and 125 and LVWP $=153.4 \pm 4.2$ and 134.5 .

ment of a new pregnancy was not $(P=0.14)$ affected by treatment when only CYC49 cows were used in the statistical analysis (Figure 3). At the end of 305 DIM, there were no differences in number of inseminations $(P=0.62)$ or on percentage of cows pregnant (SVWP inseminated in estrus $=81.9$, SVWP inseminated at timed $\mathrm{AI}=73.3, \mathrm{LVWP}=80.2 \% ; P=0.29$ ).

\section{Lactation Performance}

Treatment had no $(P=0.49)$ effect on daily average $\mathrm{FCM}$ yield $(\mathrm{SVWP}=40.5 \pm 0.4, \mathrm{LVWP}=40.2 \pm 0.4$ $\mathrm{kg} / \mathrm{d})$. Although there were no $(P=0.78)$ differences in daily average FCM yield according to the interval from parturition to resumption of cyclicity, cows with BCS $\leq 2.75$ at 62 DIM tended $(P=0.06)$ to have greater daily average FCM yield than those with BCS $>2.75$ $(40.8 \pm 0.3$ vs. $39.9 \pm 0.4 \mathrm{~kg} / \mathrm{d})$. As expected, primiparous cows had smaller $(P<0.01)$ daily average FCM yield than multiparous cows $(36.2 \pm 0.4$ vs. $44.5 \pm$ $0.3 \mathrm{~kg} / \mathrm{d}$ ). Interestingly, cows that conceived between 225 and 305 DIM $(41.6 \pm 0.5 \mathrm{~kg} / \mathrm{d})$ had greater $(P<$ $0.04)$ daily average FCM yield than those conceiving between 48 and 78 DIM $(39.5 \pm 0.5 \mathrm{~kg} / \mathrm{d}), 79$ and 125 DIM $(40.0 \pm 0.5 \mathrm{~kg} / \mathrm{d})$, and 126 and 224 DIM (40.2 $\pm 0.5 \mathrm{~kg} / \mathrm{d})$. Further, the interaction between interval to pregnancy and test number affected $(P<0.01)$ the daily average FCM yield (Figure 4).

Similarly, total milk yield was not affected by treatment $(P=0.55)$ or interval to resumption of cyclicity $(P=0.25)$. As expected, multiparous cows had greater $(P<0.01)$ total milk yield than primiparous cows $(12,937.4 \pm 119.3$ vs. $11,134.2 \pm 145.0 \mathrm{~kg})$. Interestingly, the interaction between treatment and parity tended $(P=0.06)$ to affect total milk yield, because LVWP multiparous cows had greater $(P=0.05)$ total milk yield than SVWP multiparous cows $(13,170.3 \pm$ 167.8 vs. $12,704.5 \pm 169.7 \mathrm{~kg})$, but there were no $(P=$ $0.41)$ differences between LVWP and SVWP primiparous cows $(11,015.8 \pm 205.2$ and $11,252.6 \pm 204.8 \mathrm{~kg}$, respectively).

\section{Economic Analysis}

Cost of the reproductive program for first postpartum AI was smaller $(P<0.01)$ for SVWP than for LVWP cows (Table 3). Interval from parturition to resumption of cyclicity affected $(P=0.03)$ cost of the reproductive program for first postpartum AI (Table 3), because cost of the program of ANOV62 cows was greater $(P<$ $0.01)$ than that of $\mathrm{CYC} 49$ cows and tended $(P=0.08)$ to be greater than that of CYC62 cows, but there were 


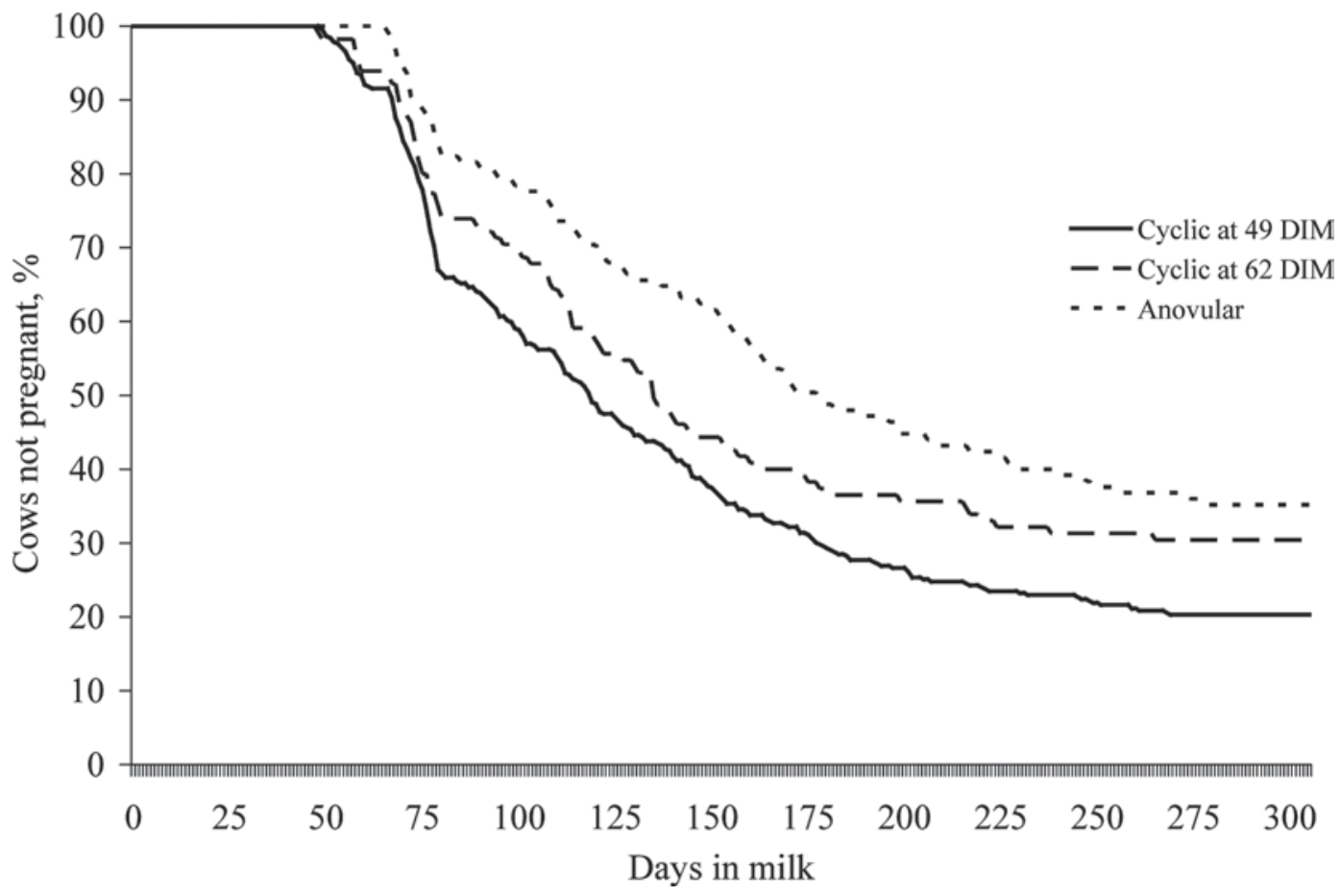

Figure 2. Survival analysis of interval from parturition to pregnancy according to cyclic status. Effect of time of resumption of cyclicity on hazard ratio of pregnancy according to the Cox proportional analysis, $P<0.01$. Contrasts: cyclic at 49 DIM $\times$ cyclic at 62 DIM $(P=0.02)$; cyclic at $49 \mathrm{DIM} \times$ anovular at $62 \mathrm{DIM}(P<0.01)$; and cyclic at $62 \mathrm{DIM} \times$ anovular at $62 \mathrm{DIM}(P=0.06)$. Effect of time of resumption of cyclicity on the interval from parturition to pregnancy according to the test of equality Wilcoxon, $P<0.01$. Mean $( \pm$ SEM) and median interval from parturition to establishment of a new pregnancy: cyclic by $49 \mathrm{DIM}=143.5 \pm 4.0$ and 118 , cyclic at $62 \mathrm{DIM}=158.3 \pm 7.5$ and 135 , and anovular at $62 \mathrm{DIM}=185.6 \pm 7.3$ and 171.

no $(P=0.64)$ differences between CYC49 and CYC62 cows. The interaction between treatment and interval from parturition to resumption of cyclicity affected $(P$ $=0.02$ ) the first postpartum AI reproductive program cost because, among LVWP cows, the interval to resumption of cyclicity did not affect first postpartum AI reproductive program cost, whereas, among SVWP cows, CYC49 $(P<0.01)$ and CYC62 $(P=0.01)$ cows had smaller first postpartum AI reproductive program cost than ANOV62 cows, but no $(P=0.51)$ differences were observed between CYC49 and CYC62 cows (Table $3)$.

Replacement cost was not $(P=0.52)$ different between SVWP and LVWP cows (Table 3). Interval to resumption of cyclicity affected $(P<0.01)$ replacement cost because CYC49 had the smallest cost $(P$ $\leq 0.01)$, but cost of replacement was not $(P=0.38)$ different between CYC62 and ANOV62 cows (Table 3). Although treatment did not $(P=0.52)$ affect salvage value, interval to resumption of cyclicity affected $(P<$ 0.01) salvage value because CYC49 had the smallest $(P \leq 0.01)$ salvage value, but salvage value was not $(P$ $=0.38$ ) different between CYC62 and ANOV62 cows (Table 3).
Because total milk yield was not affected by treatment or the interval from parturition to resumption of cyclicity (Table 3 ), total IOFC was also not affected by treatment $(P=0.48)$ or interval to resumption of cyclicity $(P=0.24$; Table 3$)$. The interaction between treatment and parity, however, tended $(P=0.06)$ to affect total IOFC because multiparous LVWP cows had $(P=0.04)$ greater IOFC than multiparous SVWP cows $(\$ 786.0 \pm 11.4$ vs. $\$ 756.7 \pm 11.4)$, whereas treatment did not $(P=0.45)$ affect the IOFC of primiparous cows $(\mathrm{SVWP}=\$ 677.5 \pm 12.5$ and $\mathrm{LVWP}=\$ 664.4 \pm$ 12.8).

Finally, economic balance at the end of 305 DIM was not $(P=0.46)$ affected by treatment (Table 3$)$. The interval from parturition to resumption of cyclicity, however, affected $(P=0.01)$ the economic balance because CYC49 cows had greater $(P<0.01)$ return than CYC62 and ANOV62 cows, but the latter 2 did not $(P=0.66)$ differ (Table 3$)$. Interestingly, economic balance was not $(P=0.46)$ affected by parity but the interaction between treatment and parity affected $(P$ $=0.04)$ the economic balance. Such an interaction was observed because primiparous SVWP cows had $(P=$ 0.03) greater return than primiparous LVWP cows 


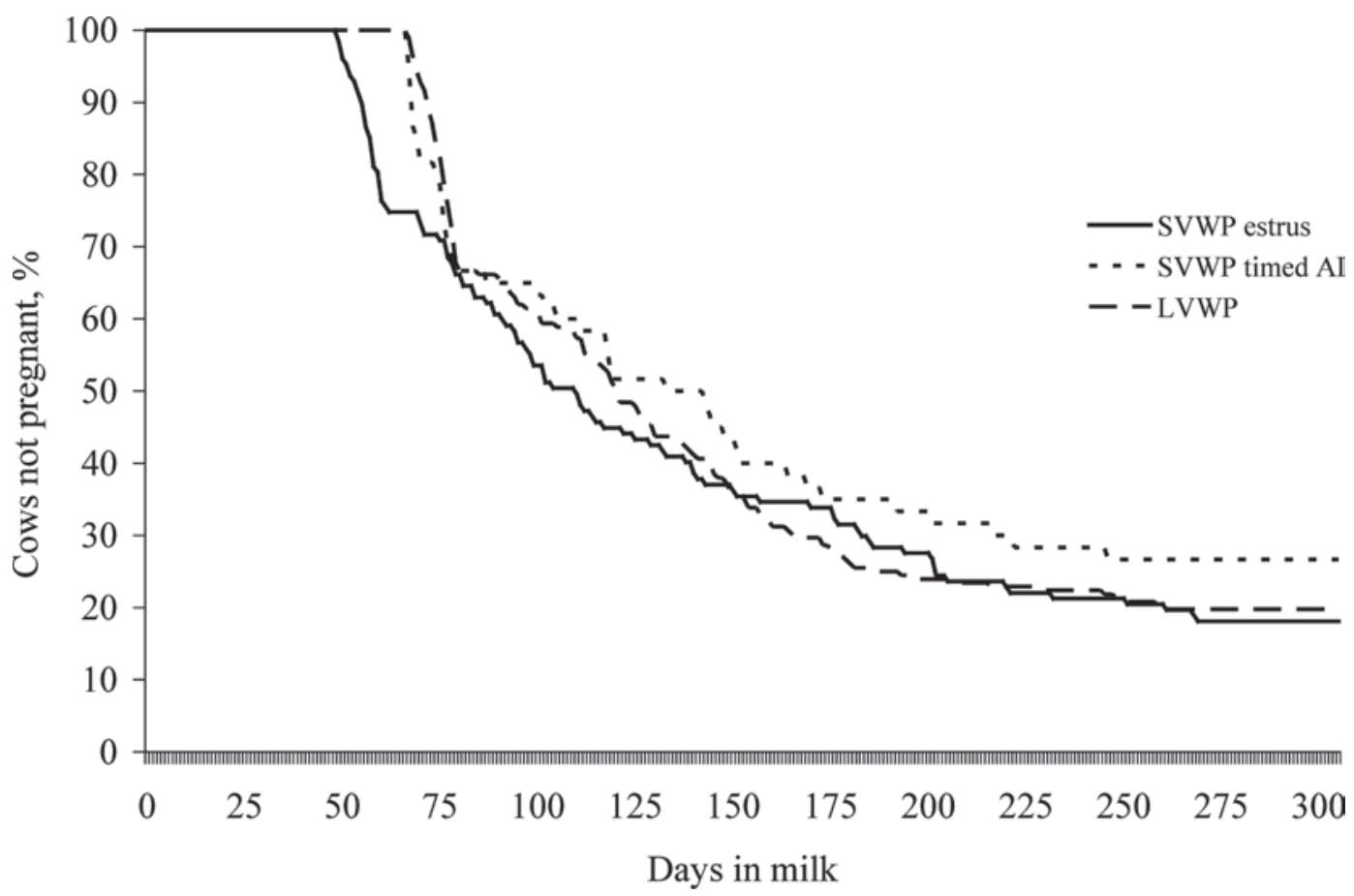

Figure 3. Survival analysis of the interval from parturition to establishment of a new pregnancy, among CYC49 cows, according to treatment [short (S) and long (L) voluntary waiting period, VWP] and type of insemination (SVWP estrus = SVWP cows inseminated at estrus; SVWP timed AI = SVWP cows inseminated at fixed time; and LVWP cows). Effect of treatment on hazard ratio of pregnancy according to the Cox proportional analysis, $P=0.14$. Effect of treatment on the interval from parturition to establishment of a new pregnancy according to the test of equality Wilcoxon, $P=0.14$. Mean $( \pm \mathrm{SEM})$ and median interval from parturition to establishment of a new pregnancy: SVWP cows inseminated in estrus $=137.6 \pm 7.1$ and 104, SVWP cows inseminated at fixed time $=146 \pm 9.3$ and 119, and LVWP cows $=142.8 \pm 5.1$ and 121 .

$(\$ 472.7 \pm 41.5$ vs. $\$ 346.7 \pm 42.1)$, whereas there was no $(P=0.52)$ difference between multiparous SVWP and LVWP cows $(422.4 \pm 36.5$ and $453.3 \pm 36.3$, respectively).

\section{DISCUSSION}

The VWP treatments and reproductive management strategies adopted in the current study were designed to reflect the most common reproductive managements used in dairy herds across the United States (DeJarnette et al., 2007; Caraviello et al., 2006). The percentage of cows classified as cyclic by 62 DIM (Cerri et al., 2004; Santos et al., 2004; Chebel et al., 2010) and the percentage of SVWP cows inseminated in estrus after the $\mathrm{PGF}_{2 \alpha}$-based presynchronization protocol (Stevenson and Phatak, 2005; Chebel et al., 2010) were similar to those described in other studies. Because almost $40 \%$ of SVWP cows were not observed in estrus and were inseminated at fixed time, the difference in average interval from parturition to first postpartum AI was only $9.5 \mathrm{~d}$ between the 2 treatments, despite the fact that the VWP was $23 \mathrm{~d}$ longer for LVWP cows. Only $67.9 \%$ of SVWP CYC49 cows were inseminated in estrus, which indicates that issues other than cyclic status affected efficiency and accuracy of estrus detection in the collaborating herd.

The $\mathrm{P} / \mathrm{AI}$ resulting from the first postpartum AI was not different between treatments. Tenhagen et al. (2003) demonstrated that low-producing cows receiving TAI between 53 and 59 DIM had lower P/AI than cows receiving TAI after 72 DIM. However, in the study by Tenhagen et al. (2003) all cows were submitted to a TAI protocol regardless of whether they had displayed estrus before the start of the TAI protocol. A large percentage (20 to $50 \%$ ) of cows is expected to be anovular by 50 to 60 DIM (Moreira et al., 2001; El-Zarkouny et al., 2004; Santos et al., 2004) and, although submission of such cows to GnRH-based TAI protocols may induce resumption of ovarian cycles in 52 to $83 \%$ of cows (Stevenson et al., 2008), anovular cows may still have reduced P/AI after TAI compared with cyclic cows, as observed in the current study and demonstrated by others (Cerri et al., 2004; Santos et al., 2004; Chebel et al., 2010). In the current study, only $11.9 \%$ of cows inseminated in estrus were anovular by 62 DIM, whereas among cows inseminated at fixed time, $23.7 \%$ were anovular by 62 DIM. This could explain why SVWP cows inseminated in estrus, despite being inseminated earlier, had similar $\mathrm{P} / \mathrm{AI}$ to that 


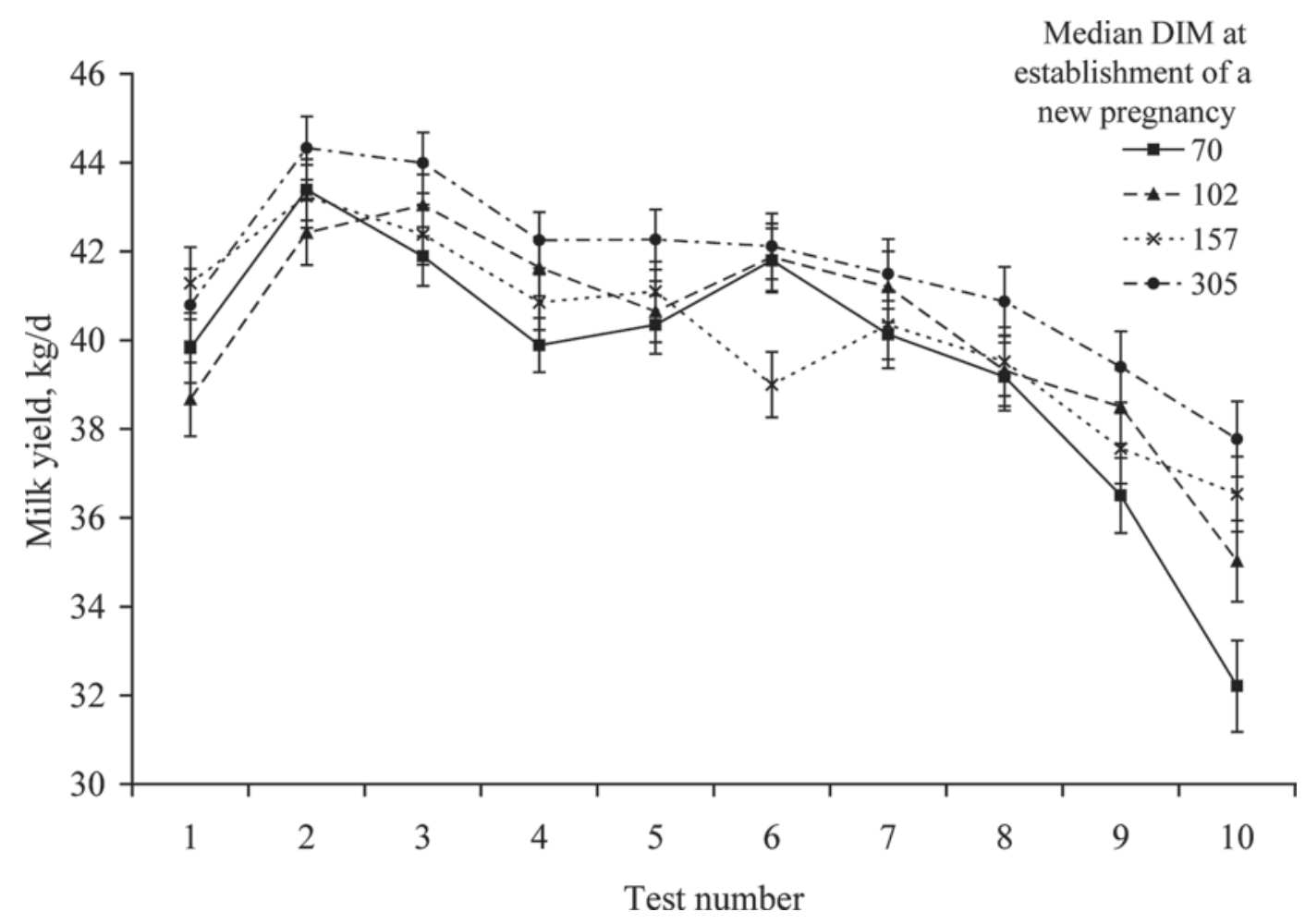

Figure 4. Milk yield of Holstein cows according to interval from parturition to establishment of a new pregnancy. Effect of interval from parturition to pregnancy, $P=0.03$, effect of test number, $P<0.01$, and effect of the interaction between interval from parturition to pregnancy and test number, $P<0.01$.

of SVWP cows inseminated at fixed time, 9.5 d later. Stevenson and Phatak (2005) demonstrated that P/AI of cows inseminated in estrus before the completion of the TAI protocol (average DIM at first AI $=61.9 \mathrm{~d}$ ) was not different from that of cows inseminated after the completion of the timed AI protocol (average DIM at first $\mathrm{AI}=76.5 \mathrm{~d}$ ). Because cows that display estrus are likely to be cyclic, they are expected to have similar or better $\mathrm{P} / \mathrm{AI}$ than those cows that do not display estrus and are inseminated later, at fixed time, because a larger percentage of the latter may be anovular or have other diseases that may compromise expression of estrus and P/AI.

The rate at which cows became pregnant and the interval between parturition and establishment of a new pregnancy did not differ between treatments. In the study by Tenhagen et al. (2003), although among cows with the smallest milk yield those inseminated at fixed time between 53 and 59 DIM had the smallest P/ AI after first postpartum AI, the percentage that was pregnant at 200 DIM was not different than that of cows receiving first postpartum AI between 73 and 102 DIM. Insemination of dairy cows $<50$ DIM is usually not recommended because dairy cows are faced with severe metabolic challenges that predispose them to diseases that have a profound effect on reproductive efficiency (Staples et al., 1990; Wathes et al., 2007). Further, in herds in which cows are dried off at approximately $225 \mathrm{~d}$ of gestation, cows that conceive $<50$ DIM would likely have excessive milk yield at dry off, which could increase the likelihood for development of new cases of mastitis during the dry period (Newman et al., 2009).

In the current study, no differences in reproductive performance of SVWP cows inseminated in estrus, SVWP cows inseminated at fixed time, and LVWP cows were observed when only CYC49 cows were evaluated. Although estrus-detection rate and accuracy, which greatly affect $\mathrm{P} / \mathrm{AI}$ and pregnancy rate of cows inseminated in estrus, are largely farm dependent, those farms that have elevated estrus-detection rate and good estrus-detection accuracy are likely to benefit from inseminating cows in estrus following $\mathrm{PGF}_{2 \alpha}$-based presynchronization protocols because of savings related to reduced percentage of cows submitted to timed AI protocols. Tenhagen et al. (2004) evaluated the reproductive performance and economic outcomes of cows only inseminated at fixed time and cows inseminated based on signs of estrus in 2 herds. In that study, reproductive and economic outcomes were dependent on 
estrus-detection rate, because only in the herd with estrus-detection rate of $28.6 \%$ were the outcomes better for cows submitted to TAI protocols (Tenhagen et al., 2004). In the current study, SVWP cows had smaller first postpartum AI reproductive program cost because a large percentage was inseminated in estrus and did not need to be submitted to the TAI protocol. Because in the calculation of economic balance, cost of reproductive program for first AI was small compared with other variables, and because total IOFC, replacement cost, and salvage value were not different between treatments, economic balance likewise did not differ. Nonetheless, TAI protocols cost approximately $\$ 6 /$ cow; therefore, if $40 \%$ of cows are inseminated in estrus before the completion of the timed AI protocol for first postpartum AI, savings in a year can be approximately $\$ 12,000$ in a herd of 5,000 lactating dairy cows.

As expected, cows that were cyclic by 49 DIM had greater $\mathrm{P} / \mathrm{AI}$ after first postpartum $\mathrm{AI}$, became pregnant at a faster rate, and were more likely to be pregnant at 305 DIM. Several studies have demonstrated that early resumption of cyclicity after parturition is associated with improved reproductive performance (Thatcher and Wilcox, 1973; Darwash et al., 1997). Earlier resumption of normal ovarian cycles after parturition and before first postpartum AI is generally associated with improved energy balance (Beam and Butler, 1997), reduced incidence of short luteal phase (Zollers et al., 1993), and reduced incidence of subclinical endometritis (Galvão et al., 2009), which are likely to improve reproductive performance. In the current study, CYC49 cows had the smallest cost of reproductive program for first AI because a greater percentage was inseminated in estrus and had the smallest replacement cost and salvage value because fewer CYC49 cows were not pregnant at 305 DIM. This resulted in economic outcomes approximately $\$ 130$ and 160 greater for CYC49 cows than for CYC62 and ANOV62 cows, respectively.

Average daily FCM yield was positively associated with interval from parturition to the establishment of a new pregnancy. Although significant variation in daily FCM yield existed during early lactation, differences in yield were more evident and consistent later in lactation ( $\geq 9$ mo in lactation). Many researchers have demonstrated an association between interval to establishment of a new pregnancy and lactation performance (Brotherstone et al., 2007; Bohmanova et al., 2009). Many have suggested that cows with greater milk yield have extended interval from parturition to establishment of a new pregnancy because of more pronounced metabolic deficits early postpartum, which may lead to increased incidence of diseases that affect reproductive performance (Lucy, 2001). It is also possible, however, that cows that conceived earlier in lactation have a 
significant decrease in milk yield starting in the ninth month of lactation because of increased demand of nutrients for fetal growth (Bell et al., 1995).

\section{CONCLUSIONS}

Insemination of dairy cows extremely early after parturition is expected to have a deleterious effect on $\mathrm{P} / \mathrm{AI}$ after first postpartum AI because of elevated incidences of anovular condition and postparturient diseases. However, limiting the VWP to approximately 50 DIM to allow for insemination on estrus following $\mathrm{PGF}_{2 \alpha}$-based presynchronization protocols is not expected to reduce $\mathrm{P} / \mathrm{AI}$ after first postpartum AI compared with reproductive protocols in which $100 \%$ of cows are inseminated at fixed time. Further, inseminating cows that are observed in estrus is not expected to affect the rate at which cows become pregnant and has the potential to reduce the costs of synchronization protocols for first postpartum AI.

\section{REFERENCES}

Beam, S. W., and W. R. Butler. 1997. Energy balance and ovarian follicle development prior to the first ovulation postpartum in dairy cows receiving three levels of dietary fat. Biol. Reprod. 56:133-142.

Bell, A. W., R. Slepetis, and R. A. Ehrhardt. 1995. Growth and accretion of energy and protein in the gravid uterus during late pregnancy in Holstein cows. J. Dairy Sci. 78:1954-1961.

Bohmanova, J., J. Jamrozik, and F. Miglior. 2009. Effect of pregnancy on production traits of Canadian Holstein cows. J. Dairy Sci. 92:2947-2959.

Brotherstone, S., M. P. Coffey, and G. Banos. 2007. Genetic parameters of growth in dairy cattle and associations between growth and health traits. J. Dairy Sci. 90:444-450.

Caraviello, D. Z., K. A. Weigel, P. M. Fricke, M. C. Wiltbank, M. J. Florent, N. B. Cook, K. V. Nordlund, N. R. Zwald, and C. L. Rawson. 2006. Survey of management practices on reproductive performance of dairy cattle on large US commercial farms. J. Dairy Sci. 89:4723-4735.

Cerri, R. L., H. M. Rutigliano, R. G. Bruno, and J. E. Santos. 2009. Progesterone concentration, follicular development and induction of cyclicity in dairy cows receiving intravaginal progesterone inserts. Anim. Reprod. Sci. 110:56-70.

Cerri, R. L., J. E. Santos, S. O. Juchem, K. N. Galvão, and R. C. Chebel. 2004. Timed artificial insemination with estradiol cypionate or insemination at estrus in high-producing dairy cows. J. Dairy Sci. 87:3704-3715.

Chebel, R. C., M. J. Al-Hassan, P. M. Fricke, J. E. Santos, C. A. Martel, J. S. Stevenson, R. Garcia, and R. L. Ax. 2010. Supplementation of progesterone via CIDR inserts during ovulation synchronization protocols in lactating dairy cows. J. Dairy Sci. 93:922-931.

Darwash, A. O., G. E. Lamming, and J. A. Woolliams. 1997. Estimation of genetic variation in the interval from calving to postpartum ovulation of dairy cows. J. Dairy Sci. 80:1227-1234.

DeJarnette, J. M., C. G. Sattler, C. E. Marshall, and R. L. Nebel. 2007. Voluntary waiting period management practices in dairy herds participating in a progeny test program. J. Dairy Sci. 90:1073-1079.
El-Zarkouny, S. Z., J. A. Cartmill, B. A. Hensley, and J. S. Stevenson. 2004. Pregnancy in dairy cows after synchronized ovulation regimens with or without presynchronization and progesterone. J. Dairy Sci. 87:1024-1037.

Ferguson, J. D., D. T. Galligan, and N. Thomsen. 1994. Principal descriptors of body condition score in Holstein cows. J. Dairy Sci. 77:2695-2703

Galvão, K. N., M. Frajblat, W. R. Butler, S. B. Brittin, C. L. Guard, and R. O. Gilbert. 2009. Effect of early postpartum ovulation on fertility in dairy cows. Reprod. Domest. Anim. doi:10.1111/j.14 39-0531.2009.01517

Lima, J. R., F. A. Rivera, C. D. Narciso, R. Oliveira, R. C. Chebel, and J. E. Santos. 2009. Effect of increasing amounts of supplemental progesterone in a timed artificial insemination protocol on fertility of lactating dairy cows. J. Dairy Sci. 92:5436-5446.

Lucy, M. C. 2001. Reproductive loss in high-producing dairy cattle: Where will it end? J. Dairy Sci. 84:1277-1293.

Miller, R. H., H. D. Norman, M. T. Kuhn, J. S. Clay, and J. L. Hutchison. 2007. Voluntary waiting period and adoption of synchronized breeding in dairy herd improvement herds. J. Dairy Sci. 90:1594-1606.

Moreira, F., C. Orlandi, C. A. Risco, R. Mattos, F. Lopes, and W. W. Thatcher. 2001. Effects of presynchronization and bovine somatotropin on pregnancy rates to a timed artificial insemination protocol in lactating dairy cows. J. Dairy Sci. 84:1646-1659.

Newman, K. A., P. J. Rajala-Schultz, F. J. Degraves, and J. Lakritz. 2009. Association of milk yield and infection status at dry-off with intramammary infections at subsequent parturition. J. Dairy Res. $12: 1-8$.

NRC. 2001. Nutrient Requirements of Dairy Cattle. 7th ed. Natl. Acad. Press, Washington, DC.

Santos, J. E., S. O. Juchem, R. L. Cerri, K. N. Galvão, R. C. Chebel, W. W. Thatcher, C. S. Dei, and C. R. Bilby. 2004. Effect of bST and reproductive management on reproductive performance of Holstein dairy cows. J. Dairy Sci. 87:868-881.

Staples, C. R., W. W. Thatcher, and J. H. Clark. 1990. Relationship between ovarian activity and energy status during the early postpartum period of high producing dairy cows. J. Dairy Sci. 73:938-947.

Stevenson, J. S., and A. P. Phatak. 2005. Inseminations at estrus induced by presynchronization before application of synchronized estrus and ovulation. J. Dairy Sci. 88:399-405.

Stevenson, J. S., D. E. Tenhouse, R. L. Krisher, G. C. Lamb, J. E. Larson, C. R. Dahlen, J. R. Pursley, N. M. Bello, P. M. Fricke, M. C. Wiltbank, D. J. Brusveen, M. Burkhart, R. S. Youngquist, and H. A. Garverick. 2008. Detection of anovulation by heatmount detectors and transrectal ultrasonography before treatment with progesterone in a timed insemination protocol. J. Dairy Sci. 91:2901-2915.

Tenhagen, B. A., M. Drillich, R. Surholt, and W. Heuwieser. 2004. Comparison of timed AI after synchronized ovulation to AI at estrus: Reproductive and economic considerations. J. Dairy Sci. 87:85-94.

Tenhagen, B. A., C. Vogel, M. Drillich, G. Thiele, and W. Heuwieser. 2003. Influence of stage of lactation and milk production on conception rates after timed artificial insemination following Ovsynch. Theriogenology 60:1527-1537.

Thatcher, W. W., and C. J. Wilcox. 1973. Postpartum estrus as an indicator of reproductive status in the dairy cow. J. Dairy Sci. 56:608-610.

Wathes, D. C., M. Fenwick, Z. Cheng, N. Bourne, S. Llewellyn, D. G. Morris, D. Kenny, J. Murphy, and R. Fitzpatrick. 2007. Influence of negative energy balance on cyclicity and fertility in the high producing dairy cow. Theriogenology 68(Suppl.1):S232-S241.

Zollers, W. G. Jr., H. A. Garverick, M. F. Smith, R. J. Moffatt, B. E. Salfen, and R. S. Youngquist. 1993. Concentrations of progesterone and oxytocin receptors in endometrium of postpartum cows expected to have a short or normal oestrous cycle. J. Reprod. Fertil. 97:329-337. 